\title{
PENGARUH KETIDAKPUASAN KONSUMEN, KARAKTERISTIK KATEGORI PRODUK TERHADAP KEPUTUSAN PERPINDAHAN MEREK DENGAN KEBUTUHAN MENCARI VARIASI SEBAGAI VARIABEL MODERASI PADA CV. MAX-INDO PADANG
}

\author{
Remantis Hartati, Febsri Susanti \\ Sekolah Tinggi Ilmu Ekonomi KBP \\ remantishartati94@gmail.com \\ febsrisusanti@akbpstie.ac.id
}

\begin{abstract}
This study aims to determine and analyze how much influence consumer dissatisfaction (X1), and the characteristics of the product category (X2), the need to find variation $(Z)$, and the decision to move the brand $(Y)$ on CV. MAX-INDO Padang, using data collection method that is in the form of questionnaire counted 100 respondents. In data analysis using validity test, reliability, and test of classical assumption that is normality, multicollinearity, heteroskedastisitas, and autokorelasi. The analysis method used is linear regression linear variable level analysis. While for hypothesis testing that is $F$ test, $T$ test, coefficient determinant of $R 2$ by using tool of SPSS. The results showed that the variable consumer dissatisfaction influences the brand transfer decision on CV. MAX-INDO Padang, the characteristic variable of the product category influences the brand transfer decision on CV. MAX-INDO Padang, based on the results of linear regression testing using moderation variables found that the variable needs searching Variations strengthen the relationship between consumer dissatisfaction, and the characteristics of the product category, to the decision to move brands on CV. MAX-INDO Padang.
\end{abstract}

Keywords: consumer dissatisfaction, the characteristics of the product category, the need to find variation, and the decision to move the brand

\section{PENDAHULUAN}

Ketidakpuasan konsumen merupakan salah satu faktor penyebab terjadinya perpindahan merek karena pelanggan yang tidak puas akan mencari informasi pilihan produk lain, dan mungkin akan berhenti membeli produk atau mempengaruhi orang lain untuk tidak membeli (P. dan K. L. K. Kotler, 2008). Perusahaan terus mengembangkan produk mereka dengan meningkatkan inovasi. Strategi pengembangan produk tersebut merupakan tujuan pemasar untuk menciptakan perilaku variety seeking pada diri konsumen.

Perkembangan bisnis handphone akhir-akhir ini telah menunjukkan suatu gejala yaitu semakin banyak dan beragamnya produk yang ditawarkan oleh 
perusahaan dan perkembangannya yang semakin cepat. Pengembangan produk handphoneyang cepat tersebut yaitu terletak pada bentuk, ukuran, dan fasilitasnya. Semakin lama bentuk handphone semakin menarik, ukuran semakin kecil dan fasilitas kegunaannya semakin lengkap. Saat ini merek handphone yang sudah masuk ke indonesia adalah : Nokia, Samsung, Sony Ericsson, LG, Asus, Mito, Motorola dan tiap merek meluncurkan banyak model atau seri yang bervariasi.

Menurut (philip kotler, 2002) menjelaskan bahwa kepuasan adalah feeling konsumen ketika mereka senang atau kecewa yang timbul setelah membedakan antara persepsi/kesannya terhadap pekerjaan yang diciptakan oleh suatu produk dan harapan yang diterimanya nanti. Pelanggan yang amat puas lebih sukar untuk mengubah pilihannya. Kepuasan tinggi akan menghasilkan pelekatan emosi konsumen terhadap merek tertentu, bukan hanya persepsi yang rasional. Hasilnya adalah pelanggan merasa kesetiaannya tinggi.

Perilaku brand switching yang timbul akibat adanya perilaku variety seeking perlu mendapat perhatian dari pemasar. Perilaku ini tidak hanya cenderung terjadi pada produk yang memerlukan tingkat keterlibatan yang rendah, akan tetapi terjadi juga pada produk dengan tingkat keterlibatan tinggi (high involvement). Tingkat keterlibatan produk dikatakan tinggi, apabila konsumen melibatkan banyak faktor pertimbangan dan informasi yang harus diperolehnya sebelum keputusan untuk membeli diambil. Termasuk dalam faktor pertimbangan tersebut adalah faktor resiko, yaitu resiko performance, fisik, keuangan dan waktu.

Akibat dari munculnya perilaku perpindahan merek konsumen adalah adanya perilaku variety seeking mendapat perhatian khusus dari tenaga pasar. Perilaku perpindahan merek tidak hanya terjadi pada produk yang membutuhkan keterlibatan merek tingkat rendah, akan tetapi terjadi pada produk dengan tingkat keterlibatan merek tingkat tinggi (high involvement). Tingkat keterlibatan produk dikatakan tinggi, apabila konsumen melibatkan banyak faktor pertimbangan dan informasi yang harus diperolehnya sebelum keputusan untuk membeli diambil. Termasuk dalam faktor pertimbangan tersebut adalah faktor resiko, yaitu resiko performance,fisik, keuangan dan waktu.

\section{METODE PENELITIAN}

\section{Jenis Penelitian}

Jenis penelitian ini adalah Penelitian Kuantitatif. Penelitian kuantitatif yaitu suatu metode penelitian yang berlandaskan pada filsafat postpositivisme, digunakan untuk meneliti pada kondisi objek yang alamiah dimana peneliti adalah sebagai instrumen kunci, pengambilan sampel sumber data dilakukan secara purposive, teknik pengumpulan dengan triangulasi, analisis data bersifat induktif/kuantitatif, dan hasil penelitian kuantitatif lebih menekankan makna dari pada generalisasi (Sugiono, 2009).

\section{Objek atau Lokasi Penelitian}

Pada penelitian ini penulis memilih objek penelitian pada CV MAX-INDO yang beralamat di Jalan Kampung Nias V No.7, belakang pondok, Kota Padang.

\section{Populasi dan Sampel}

Populasi penelitian ini adalah pelangaan yang pernah melakukan perpindahan merek dari pembelian Handphone Samsung ke merek lain sebanyak 150 orang Responden pada tahun 2017. Sampel dalam penelitian ini menggunakan rumus slovin yang didapat 100 orang sampel. 


\section{Teknik Pengambilan Sampel}

Pengambilan sampel dengan menggunakan teknik Random Sampling yaitu pengambilan anggota sampel dari populasi dilakukan secara acak tanpa memperhatikan strata yang ada dalam populasi itu. (Sugiono, 2009).

Kriteria Pengambilan sampel sebagai berikut:

1. Yang telah menjadi nasabah CV MAX-INDO.

2. Pernah melakukan perpindahan merek ke merek lain pada CV MAX-INDO.

\section{Teknik Pengumpulan Data}

Teknik pengumpulan data dalam penelitian ini adalah Survey, Survey merupakan teknik pengumpulan data dimana data diperoleh berdasarkan pemberian kuesioner terhadap sampel yang diteliti.

\section{Definisi Operasional Variabel}

\section{Tabel 1}

Definisi Operasional Variabel

\begin{tabular}{|c|c|c|c|}
\hline Variabel & Definisi & Indikator & Sumber \\
\hline $\begin{array}{l}\text { Perpindahan } \\
\text { Merek (Y) }\end{array}$ & $\begin{array}{l}\text { Kondisi dimana seorang } \\
\text { konsumen atau sekelompok } \\
\text { konsumen mengubah kesetiaan } \\
\text { mereka dari satu tipe produk } \\
\text { tertentu ketipe produk yang } \\
\text { berbeda }\end{array}$ & $\begin{array}{ll}\text { 1. } & \text { Ketidakpuasan } \\
\text { yang dialami } \\
\text { pasca konsumsi. } \\
\text { 2. } \\
\text { Keinginan untuk } \\
\text { mencari variasi. } \\
\text { 3. } \\
\text { Keinginan untuk } \\
\text { mempercepat } \\
\text { penghentian } \\
\text { penggunaan } \\
\text { handphone. }\end{array}$ & $\begin{array}{lr}\text { Jurnal Buletin } & \text { Studi } \\
\text { Ekonomi }(2013) & \end{array}$ \\
\hline $\begin{array}{l}\text { Ketidakpuasan } \\
\text { Konsumen (X1) }\end{array}$ & $\begin{array}{l}\text { Ketidakpuasan konsumen dapat } \\
\text { timbul karena adanya proses } \\
\text { informasi dalam evaluasi } \\
\text { terhadap suatu merek. }\end{array}$ & 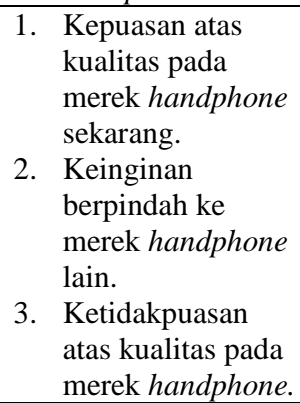 & $\begin{array}{l}\text { Jurnal Buletin } \\
\text { Ekonomi }(2013)\end{array}$ \\
\hline $\begin{array}{l}\text { Karakteristik } \\
\text { Kategori Produk } \\
\text { (X2) }\end{array}$ & $\begin{array}{l}\text { Sifat suatu produk yang dapat } \\
\text { membedakan produk tersebut } \\
\text { dengan produk lain }\end{array}$ & $\begin{array}{ll}\text { 1. } & \text { Keterlibatan } \\
\text { 2. } & \text { Perbedaan } \\
\text { persepsi diantara } \\
\text { merek } \\
\text { 3. } \\
\text { 4itur hedonis } \\
\text { Kekuatan } \\
\text { preferensi }\end{array}$ & $\begin{array}{l}\text { Jurnal Buletin } \\
\text { Ekonomi }(2013)\end{array}$ \\
\hline $\begin{array}{l}\text { Kebutuhan } \\
\text { Mencari Variasi } \\
\text { (Variabel } \\
\text { Moderasi) }\end{array}$ & $\begin{array}{l}\text { Merupakan suatu sikap konsumen } \\
\text { yang ingin mencoba merek lain } \\
\text { dan memuaskan rasa } \\
\text { penasarannya terhadap merek lain } \\
\text { serta diasosiasikan sebagai } \\
\text { keinginan untuk berganti } \\
\text { kebiasaan }\end{array}$ & $\begin{array}{l}\text { 1. Adanya rasa bosan } \\
\text { terhadap merek } \\
\text { handphone. } \\
\text { 2. Banyaknya merek } \\
\text { handphone. } \\
\text { 3. Tidak khawatir } \\
\text { dalam mencoba } \\
\text { merek yang } \\
\text { berbeda. }\end{array}$ & $\begin{array}{l}\text { Jurnal Buletin Studi } \\
\text { Ekonomi (2013) }\end{array}$ \\
\hline
\end{tabular}




\section{Teknik Analisis Data}

\section{Uji Instrumen Penelitian}

a) Uji Validitas

b) Uji Reliabilitas

c) Uji TCR

\section{Uji Asumsi Klasik}

1. Uji Normalitas

Pengujian normalitas adalah pengujian tentang kenormalan distribusi data (Budi Purbayu Santosa dan Ashari, 2005). Pengujian normalitas dilakukan untuk mengetahui sebuah data berdistribusi normal atau tidak. Dalam pengujian ini menggunakan indikator uji Kolmogrov-smirnov dengan pedoman sebagai berikut :

a. Jika nilai probabilitas $>0,05$ maka Ho diterima

b. Jika nilai probabilitas $<0,05$ maka Ho ditolak

2. Uji Multikonearitas

Uji Multikolinearitas adalah adanya hubungan linear yang sempurna (mendekati sempurna) antara beberapa atau semua variabel bebas (Mudrajad Kuncoro, 2001). Uji multikolinieritas bertujuan untuk menguji apakah model regresi yang ditemukan adanya korelasi antar variabel bebas.Model regresi yang baik adalah tidak terjadi korelasi di antara variabel bebas (Ghozali, 2001). Dalam pengujian ini menggunakan indikator sebagai berikut :
a. Tolerance $>0.1$
b. Variance Inflation Factor (VIF) $<10$

3. Uji Heteroskedastisitas

Uji Heteroskedastisitas yaitu untuk menguji apakah dalam model regresi terjadi ketidaksamaan variance dari residual satu pengamatan ke pengamatan yang lain. Oleh karena itu, apabila jika pvalue $>0,05$, maka tidak terjadi gejala heteroskedastisitas.

4. Uji Autokorelasi

Uji Autokorelasi merupakan korelasi time series (lebih menekankan pada dua data penelitian berupa data rentetan waktu).

\section{Analisis Regresi Linear}

Adapun persamaan dalam penelitian ini adalah:

$$
\begin{array}{rll}
\mathrm{Y}=\alpha+\beta_{1} \mathrm{X}_{1}+\beta_{2} \mathrm{X}_{2}+\beta_{1} \mathrm{X}_{1} * \mathrm{Z}+\beta_{2} \mathrm{X}_{2} * \mathrm{Z} \\
\mathrm{Y}= & \text { Keputusan Perpindahan Merek } \\
\alpha & = & \text { Koefisien Konstanta } \\
\beta_{1}= & \text { Koefisien Regresi untuk Ketidakpuasan Konsumen } \\
\beta_{2}= & \text { Koefisien Regresi untuk Karakteristik Kategori } \\
& & \text { Produk } \\
\mathrm{X}_{1}= & \text { Ketidakpuasan Konsumen } \\
\mathrm{X}_{2}= & \text { Karakteristik Kategori Produk } \\
\mathrm{Z} & = & \text { Kebutuhan mencari Variasi }
\end{array}
$$$$
\beta_{2}=\text { Koefisien Regresi untuk Karakteristik Kategori }
$$

\section{Uji Hipotesis}

1. Uji F

2. Uji T

3. Uji R Square $\left(\mathrm{R}^{2}\right)$ 
HASIL DAN PEMBAHASAN

Uji Validitas

a. Uji Validitas Ketidakpuasan Konsumen

Berdasarkan hasil pengujian validitas yang telah dilakukan diperoleh ringkasan bawah ini:

Tabel 2

Hasil Uji Validitas Ketidakpuasan Konsumen

\begin{tabular}{|c|c|c|}
\hline Variabel & Corrected Item-Total Correlation & Keterangan \\
\hline $\mathrm{X} 1.1$ & 0.660 & Valid \\
\hline $\mathrm{X} 1.2$ & 0.543 & Valid \\
\hline $\mathrm{X} 1.3$ & 0.544 & Valid \\
\hline $\mathrm{X} 1.4$ & 0.449 & Valid \\
\hline $\mathrm{X} 1.5$ & 0,553 & Valid \\
\hline
\end{tabular}

Sumber: Data Primer diolah dengan SPSS Th.2018

b. Uji Validitas Karakteristik Kategori Produk

Berdasarkan hasil pengujian validitas yang telah dilakukan diperoleh ringkasan terlihat pada table 3 sebagai berikut:

Tabel 3

Hasil Uji Validitas Karakteristik Kategori Produk

\begin{tabular}{|c|c|c|}
\hline Variabel & Corrected Item-Total Correlation & Keterangan \\
\hline X2.1 & 0,417 & Valid \\
\hline X2.2 & 0,612 & Valid \\
\hline X2.3 & 0,668 & Valid \\
\hline X2.4 & 0,639 & Valid \\
\hline
\end{tabular}

Sumber: Data Primer diolah dengan SPSS Th.2018

c. Uji Validitas Kebutuhan Mencari Variasi

Berdasarkan hasil pengujian validitas yang telah dilakukan diperoleh ringkasan terlihat pada table 4 sebagai berikut:

Tabel 4

Hasil Uji Validitas Kebutuhan Mencari Variasi

\begin{tabular}{|c|c|c|}
\hline Variabel & $\begin{array}{c}\text { Corrected Item-Total } \\
\text { Correlation }\end{array}$ & Keterangan \\
\hline Z1 & 0,485 & Valid \\
\hline Z2 & 0,365 & Valid \\
\hline Z3 & 0,620 & Valid \\
\hline Z4 & 0,679 & Valid \\
\hline Z5 & 0,653 & Valid \\
\hline Z6 & 0,501 & Valid \\
\hline Z7 & 0,408 & Valid \\
\hline Z8 & 0,508 & Valid \\
\hline Z9 & 0,606 & Valid \\
\hline Z10 & 0,653 & \\
\hline
\end{tabular}

Sumber: Data Primer diolah dengan SPSS Th.2018 


\section{d. Uji Validitas Keputusan Perpindahan Merek}

Berdasarkan hasil pengujian validitas yang telah dilakukan diperoleh ringkasan terlihat pada table 5 sebagai berikut:

\section{Tabel 5}

Hasil Uji Validitas Keputusan Perpindahan Merek

\begin{tabular}{|c|c|c|}
\hline Variabel & $\begin{array}{c}\text { Corrected Item-Total } \\
\text { Correlation }\end{array}$ & Keterangan \\
\hline Y1 & 0,513 & Valid \\
\hline Y2 & 0,386 & Valid \\
\hline Y3 & 0,603 & Valid \\
\hline Y4 & 0,662 & Valid \\
\hline Y5 & 0,530 & Valid \\
\hline Y6 & 0,506 & Valid \\
\hline Y7 & 0,441 & Valid \\
\hline Y8 & 0,529 & Valid \\
\hline Y9 & 0,623 & Valid \\
\hline
\end{tabular}

Sumber: Data Primer diolah dengan SPSS Th.2018

Uji Reliabilitas

a. Uji Reliabilitas Ketidakpuasan Konsumen

Tabel 6

Hasil Uji Reliabilitas Ketidakpuasan Konsumen

\begin{tabular}{|lc|c|c|}
\hline \multicolumn{2}{|c|}{ Variabel } & Cronbach's Alpha & Keterangan \\
\hline $\begin{array}{l}\text { Reliabilitas } \\
\text { Konsumen }\end{array}$ & Variabel Ketidakpuasan & 0,755 & Reliabel \\
\hline
\end{tabular}

Sumber: Data Primer diolah dengan SPSS Th.2018

b. Uji Reliabilitas Karakteristik Kategori Produk

Tabel 7

Hasil Uji Reliabilitas Untuk Karakteristik Kategori Produk

\begin{tabular}{|l|c|c|}
\hline \multicolumn{1}{|c|}{ Variabel } & Cronbach's Alpha & Keterangan \\
\hline $\begin{array}{l}\text { Reliabilitas Variabel Karakteristik } \\
\text { Kategori Produk }\end{array}$ & 0,769 & Reliabel \\
\hline
\end{tabular}

Sumber: Data Primer diolah dengan SPSS Th.2018

c. Uji Reliabilitas Kebutuhan Mencari Variasi

Tabel 8

Hasil Uji Reliabilitas Untuk Kebutuhan Mencari Variasi

\begin{tabular}{|l|c|c|}
\hline \multicolumn{1}{|c|}{ Variabel } & Cronbach's Alpha & Keterangan \\
\hline $\begin{array}{l}\text { Reliabilitas Variabel Kebutuhan Mencari } \\
\text { Variasi }\end{array}$ & 0,746 & Reliabel \\
\hline
\end{tabular}

Sumber: Data Primer diolah dengan SPSS Th.2018

d. Uji Reliabilitas Keputusan Perpindahan Merek

Tabel 9

Hasil Uji Reliabilitas Untuk Keputusan Perpindahan Merek

\begin{tabular}{|l|c|c|}
\hline \multicolumn{1}{|c|}{ Variabel } & Cronbach's Alpha & Keterangan \\
\hline $\begin{array}{l}\text { Reliabilitas Variabel Kebutuhan Mencari } \\
\text { Variasi }\end{array}$ & 0,743 & Reliabel \\
\hline
\end{tabular}

Sumber: Data Primer diolah dengan SPSS Th.2018 
Analisis Deskriptif TCR

a. Ketidakpuasan Konsumen

Tabel 10

Distribusi Frekuensi Variabel Reliability

\begin{tabular}{|c|c|c|c|c|c|c|c|c|c|c|c|c|}
\hline No & Variabel & SS & $\mathbf{S}$ & KS & TS & STS & $\mathbf{N}$ & $\%$ & $\begin{array}{l}\text { Skor } \\
\text { Total }\end{array}$ & $\begin{array}{l}\text { Rata- } \\
\text { Rata }\end{array}$ & TCR & Keterangan \\
\hline 1 & \multirow{4}{*}{$\begin{array}{c}\text { Ketidak } \\
\text { puasan } \\
\text { Konsumen }\end{array}$} & 46 & 48 & 4 & 0 & 2 & 100 & 100 & 436 & 4,36 & 87,2 & Sangat Baik \\
\hline 2 & & 49 & 45 & 2 & 1 & 3 & 100 & 100 & 436 & 4,36 & 87,2 & Sangat Baik \\
\hline 3 & & 60 & 35 & 3 & 0 & 2 & 100 & 100 & 451 & 4,51 & 90,2 & Sangat Baik \\
\hline 4 & & 52 & 42 & 4 & 1 & 1 & 100 & 100 & 443 & 4,43 & 88,6 & Sangat Baik \\
\hline \multirow[t]{2}{*}{5} & & 49 & 40 & 7 & 2 & 2 & 100 & 100 & 431 & 4,31 & 86,2 & Sangat Baik \\
\hline & \multicolumn{9}{|c|}{ Rata-Rata TCR } & 4,39 & 87,8 & Sangat Baik \\
\hline
\end{tabular}

Sumber: Data Primer diolah dengan SPSS Th.2018

b. Karakteristik Kategori Produk

Tabel 11

Distribusi Frekuensi Variabel Karakteristik Kategori Produk

\begin{tabular}{|c|c|c|c|c|c|c|c|c|c|c|c|c|}
\hline No & Variabel & SS & $\mathbf{S}$ & KS & TS & STS & $\mathbf{N}$ & $\%$ & $\begin{array}{l}\text { Skor } \\
\text { Total }\end{array}$ & $\begin{array}{l}\text { Rata- } \\
\text { Rata }\end{array}$ & TCR & Keterangan \\
\hline 1 & \multirow{4}{*}{$\begin{array}{c}\text { Karakteristik } \\
\text { Kategori } \\
\text { Produk }\end{array}$} & 51 & 44 & 3 & 1 & 1 & 100 & 100 & 443 & 4,43 & 88,6 & Sangat Baik \\
\hline 2 & & 45 & 50 & 2 & 1 & 2 & 100 & 100 & 435 & 4,35 & 87 & Sangat Baik \\
\hline 3 & & 46 & 48 & 4 & 0 & 2 & 100 & 100 & 436 & 4,36 & 87,2 & Sangat Baik \\
\hline \multirow[t]{2}{*}{4} & & 49 & 45 & 2 & 1 & 3 & 100 & 100 & 436 & 4,36 & 87,2 & Sangat Baik \\
\hline & \multicolumn{9}{|c|}{ Rata-Rata TCR } & 4,37 & 7,00 & Baik \\
\hline
\end{tabular}

Sumber: Data Primer diolah dengan SPSS Th.2018

c. Kebutuhan Mencari Variasi

Tabel 12

Distribusi Frekuensi Variabel Kebutuhan Mencari Variasi

\begin{tabular}{|c|c|c|c|c|c|c|c|c|c|c|c|c|}
\hline No & Variabel & SS & $\mathbf{S}$ & KS & TS & STS & $\mathbf{N}$ & $\%$ & $\begin{array}{l}\text { Skor } \\
\text { Total }\end{array}$ & $\begin{array}{l}\text { Rata- } \\
\text { Rata }\end{array}$ & TCR & Keterangan \\
\hline 1 & \multirow{10}{*}{$\begin{array}{c}\text { Kebutuhan } \\
\text { Mencari } \\
\text { Variasi }\end{array}$} & 51 & 44 & 3 & 1 & 1 & 100 & 100 & 443 & 4,43 & 88,6 & Sangat Baik \\
\hline 2 & & 49 & 40 & 7 & 2 & 2 & 100 & 100 & 432 & 4,32 & 86,4 & Sangat Baik \\
\hline 3 & & 45 & 50 & 2 & 1 & 2 & 100 & 100 & 435 & 4,35 & 87 & Sangat Baik \\
\hline 4 & & 46 & 48 & 4 & 0 & 2 & 100 & 100 & 436 & 4,36 & 87,2 & Sangat Baik \\
\hline 5 & & 49 & 45 & 2 & 1 & 3 & 100 & 100 & 436 & 4,36 & 87,2 & Sangat Baik \\
\hline 6 & & 60 & 35 & 3 & 0 & 2 & 100 & 100 & 451 & 4,51 & 90,2 & Sangat Baik \\
\hline 7 & & 60 & 35 & 3 & 0 & 2 & 100 & 100 & 451 & 4,51 & 90,2 & Sangat Baik \\
\hline 8 & & 49 & 40 & 7 & 2 & 2 & 100 & 100 & 432 & 4,32 & 86,4 & Sangat Baik \\
\hline 9 & & 52 & 42 & 4 & 1 & 1 & 100 & 100 & 444 & 4,44 & 88,8 & Sangat Baik \\
\hline 10 & & 49 & 45 & 2 & 1 & 3 & 100 & 100 & 436 & 4,36 & 87,2 & Sangat Baik \\
\hline
\end{tabular}

Sumber: Data Primer diolah dengan SPSS Th.2018

d. Keputusan Perpindahan Merek

Tabel 13

Distribusi Frekuensi Variabel Keputusan Perpindahan Merek

\begin{tabular}{|c|c|c|c|c|c|c|c|c|c|c|c|c|}
\hline No & Variabel & SS & $\mathbf{S}$ & $\mathbf{K S}$ & TS & STS & $\mathbf{N}$ & $\%$ & $\begin{array}{l}\text { Skor } \\
\text { Total }\end{array}$ & $\begin{array}{l}\text { Rata- } \\
\text { Rata }\end{array}$ & TCR & Keterangan \\
\hline 1 & \multirow{9}{*}{$\begin{array}{c}\text { Keputusan } \\
\text { Perpindahan } \\
\text { Merek }\end{array}$} & 51 & 44 & 3 & 1 & 1 & 100 & 100 & 414 & 4,14 & 82,8 & Sangat Baik \\
\hline 2 & & 49 & 45 & 2 & 1 & 3 & 100 & 100 & 436 & 4,36 & 87,2 & Sangat Baik \\
\hline 3 & & 45 & 50 & 2 & 1 & 2 & 100 & 100 & 435 & 4,35 & 87 & Sangat Baik \\
\hline 4 & & 46 & 48 & 4 & 0 & 2 & 100 & 100 & 436 & 4,36 & 87,2 & Sangat Baik \\
\hline 5 & & 49 & 45 & 2 & 1 & 3 & 100 & 100 & 436 & 4,36 & 87,2 & Sangat Baik \\
\hline 6 & & 60 & 35 & 3 & 0 & 2 & 100 & 100 & 451 & 4,51 & 90,2 & Sangat Baik \\
\hline 7 & & 49 & 45 & 2 & 1 & 3 & 100 & 100 & 436 & 4,36 & 87,2 & Sangat Baik \\
\hline 8 & & 49 & 40 & 7 & 2 & 2 & 100 & 100 & 432 & 4,32 & 86,4 & Sangat Baik \\
\hline \multirow[t]{2}{*}{9} & & 52 & 42 & 4 & 1 & 1 & 100 & 100 & 443 & 4,43 & 88,6 & Sangat Baik \\
\hline & \multicolumn{9}{|c|}{ Rata-Rata TCR } & 4,35 & 15.676 & Sangat Baik \\
\hline
\end{tabular}

Sumber: Data Primer diolah dengan SPSS Th.2018 
Uji Asumsi Klasik

a. Uji Normalitas

Tabel 14

Uji Normalitas

One-Sample Kolmogorov-Smirnov Test

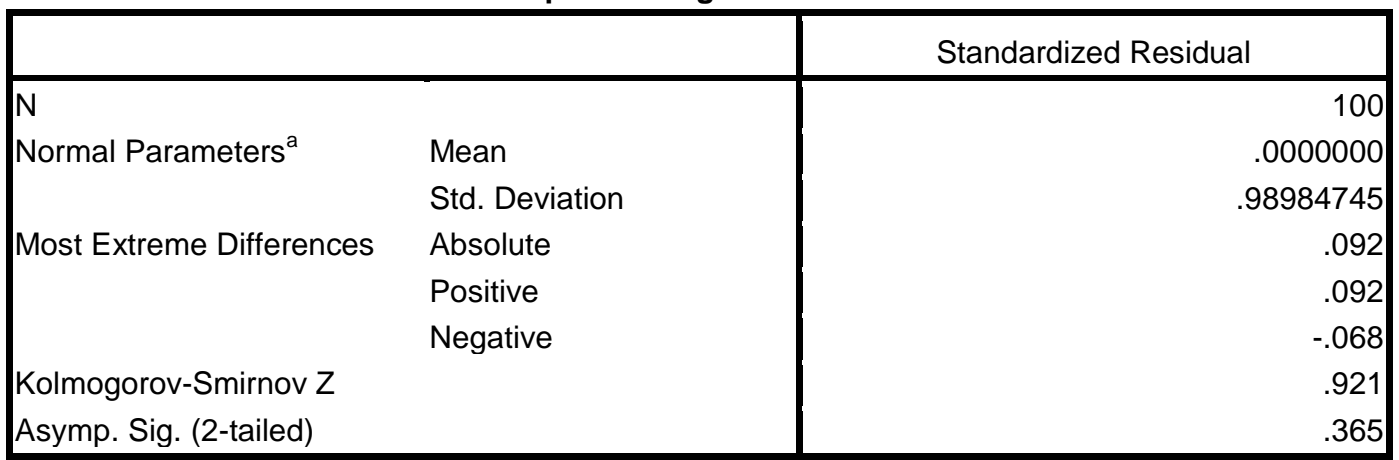

Sumber: Data Primer diolah dengan SPSS Th.2018

Berdasarkan hasil pengolahan data diatas terlihat bahwa nilai asymp.sig sebesar 0,232. Nilai asymp.sig yang 0,365>0,05. Maka dapat disimpulkan bahwa hasil uji normalitas kolmogrov-smirnov data tersebut terdistribusi normal karena nilai signifikan lebih besar dari 0,05 .

\section{b. Uji Multikolinearitas}

Tabel 15

Hasil Uji Multikolinearitas

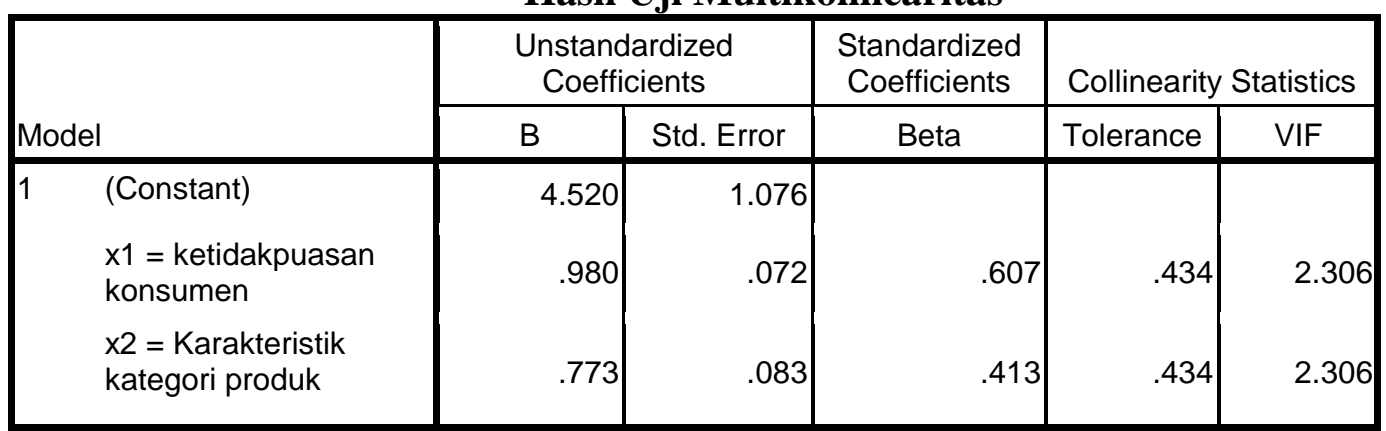

Sumber: Data Primer diolah dengan SPSS Th.2018

Berdasarkan hasil pengolahan data diatas pada table 15 dapat dilihat bahwa masing-masing variabel independen memiliki nilai tolerance $>0.1$, dan masingmasing variabel independent VIF $<10$ berdasarkan hasil pengolahan data diatas maka dapat disimpulkan bahwa penelitian ini terbebas dari masalah Multikolinearitas. 
c. Uji Heteroskedastisitas

1. Metode Uji Glejser

Tabel 16

Hasil Uji Heteroskedastisitas

Coefficients $^{\mathrm{a}}$

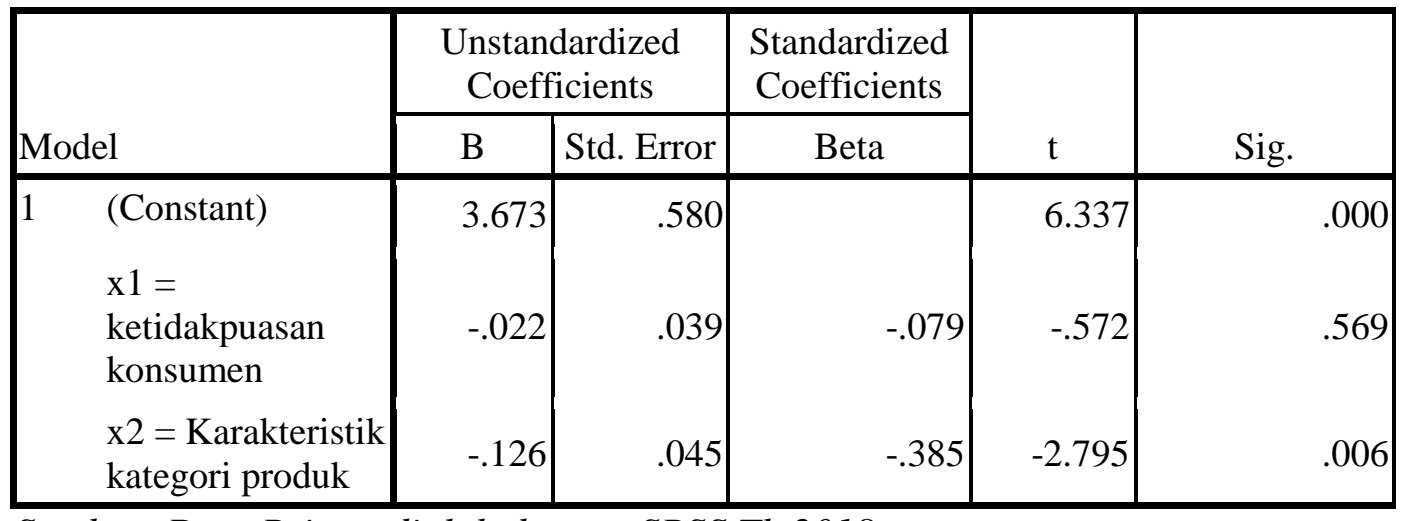

Sumber: Data Primer diolah dengan SPSS Th.2018

2. Metode Garis Plot

Scatterplot

Dependent Variable: $y=$ keputusan perpindahan merek

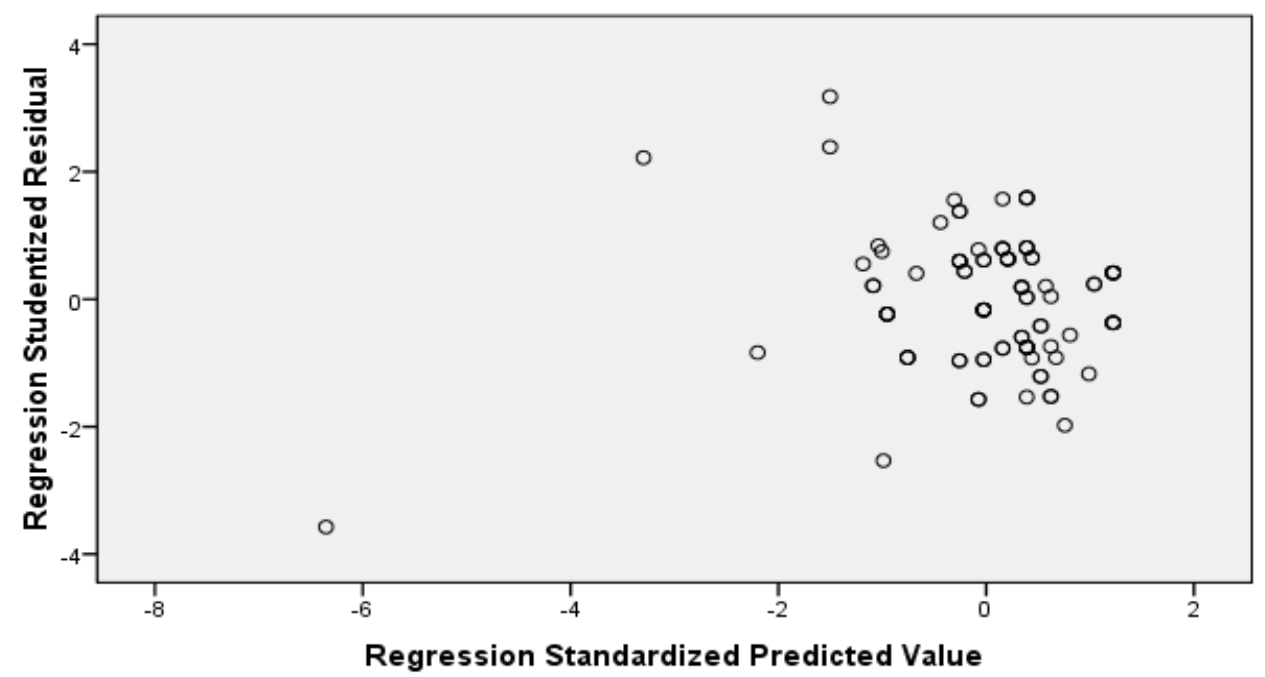

d. Uji Autokerelasi

Tabel 17

Hasil Uji Autokorelasi

Model Summary ${ }^{\text {b }}$

\begin{tabular}{|l|r|r|r|r|r|}
\hline Model & \multicolumn{1}{|c|}{$\mathrm{R}$} & R Square & $\begin{array}{c}\text { Adjusted R } \\
\text { Square }\end{array}$ & $\begin{array}{c}\text { Std. Error of the } \\
\text { Estimate }\end{array}$ & Durbin-Watson \\
\hline 1 & $.957^{\mathrm{a}}$ & .916 & .915 & 1.28801 & 2.001 \\
\hline
\end{tabular}

Sumber: Data Primer diolah dengan SPSS Th.2018 
Berdasarkan hasil pengolahan data diatas pada table 17 dapat dilihat bahwa nilai Durbin Watson sebesar 2,001. Nilai 2,001 berada diantara 1,55 - 2,46 berdasarkan hasil pengolahan data diatas maka dapat disimpulkan bahwa penelitian ini terbebas dari masalah Autokorelasi.

\section{Uji Regresi Linear}

a. Analisis Regresi Linear Berganda

Tabel 18

1. Ketidakpuasan Konsumen

\section{Hasil Uji Regresi Linear Berganda}

Coefficients $^{a}$

\begin{tabular}{|c|c|c|c|c|c|c|}
\hline \multirow{2}{*}{\multicolumn{2}{|c|}{ Model }} & \multicolumn{2}{|c|}{$\begin{array}{l}\text { Unstandardized } \\
\text { Coefficients }\end{array}$} & \multirow{2}{*}{$\begin{array}{c}\begin{array}{c}\text { Standardized } \\
\text { Coefficients }\end{array} \\
\text { Beta }\end{array}$} & \multirow[b]{2}{*}{$\mathrm{t}$} & \multirow[b]{2}{*}{ Sig. } \\
\hline & & $\mathrm{B}$ & Std. Error & & & \\
\hline 1 & (Constant) & 6.946 & 1.426 & & 4.871 & .000 \\
\hline & $\begin{array}{l}\mathrm{x} 1=\text { ketidakpuasan } \\
\text { konsumen }\end{array}$ & 1.482 & .065 & .918 & 22.877 & .000 \\
\hline
\end{tabular}

Sumber: Data Primer diolah dengan SPSS Th.2018

Berdasarkan hasil analisis regresi linear berganda diperoleh persamaan sebagai berikut:

$$
\mathrm{Y}=6.946+1,482 \mathrm{X}_{1}
$$

Persamaan regresi berganda diatas dapat diartikan bahwa:

1. Nilai konstanta variabel $X_{1}$ yaitu 6,946 dengan parameter positif yang mana dapat disimpulkan bahwa nilai ketidakpuasan konsumen adalah sebesar 6,946 dengan asumsi variabel lain bernilai nol.

2. Nilai koefisien regresi $X_{1}$ yaitu 1,482 dengan parameter positif yang mana dapat disimpulkan bahwa setiap peningkatan satu kesatuan ketidakpuasan konsumen maka akan mengakibatkan kenaikan nilai koefisien keputusan perpindahan merek sebesar 1,482.

\section{Karakteristik Kategori Produk}

Coefficients $^{\mathrm{a}}$

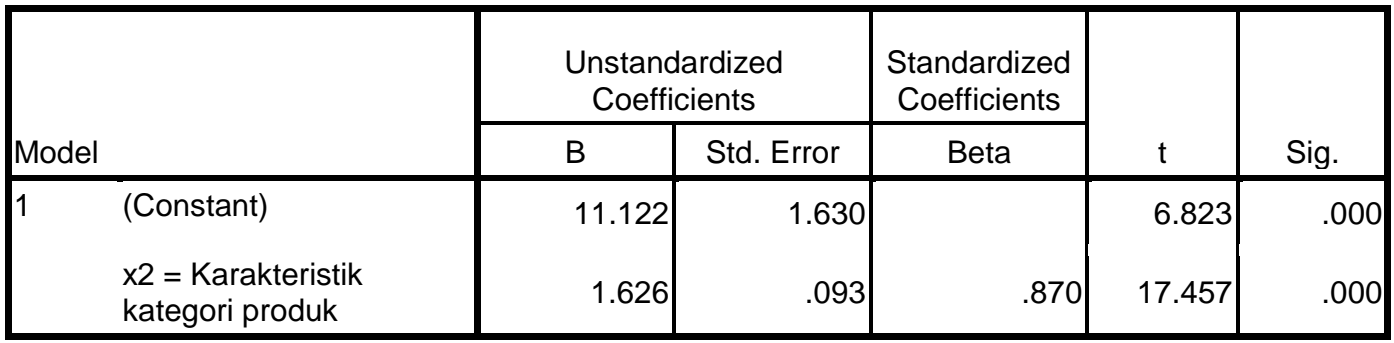

Sumber: Data Primer diolah dengan SPSS Th.2018

Berdasarkan hasil analisis regresi linear berganda diperoleh persamaan sebagai berikut:

$$
\mathrm{Y}=11.112+1,626 \mathrm{X}
$$

Persamaan regresi berganda diatas dapat diartikan bahwa:

1. Nilai konstanta variabel $\mathrm{X}_{2}$ yaitu 11,122 dengan parameter positif yang mana dapat disimpulkan bahwa nilai keputusan perpindahan merek adalah sebesar 11,122 dengan asumsi variabel lain bernilai nol.

2. Nilai koefisien regresi karakteristik kategori produk yaitu 1,626 dengan parameter positif yang mana dapat disimpulkan bahwa setiap peningkatan 
satu kesatuan karakteristik kategori produk maka akan mengakibatkan kenaikan nilai koefisien keputusan perpindahan merek sebesar 1,626.

\section{b. Analisis Regresi Linear Bertingkat}

Tabel 19

\section{Ketidakpuasan Konsumen}

Hasil Uji Regresi Linear bertingkat

\begin{tabular}{|c|c|c|c|c|c|c|}
\hline \multicolumn{7}{|c|}{ Coefficients $^{a}$} \\
\hline \multirow{2}{*}{\multicolumn{2}{|c|}{ Model }} & \multicolumn{2}{|c|}{ Unstandardized Coefficients } & \multirow{2}{*}{\begin{tabular}{c|}
$\begin{array}{c}\text { Standardized } \\
\text { Coefficients }\end{array}$ \\
Beta \\
\end{tabular}} & \multirow[b]{2}{*}{$t$} & \multirow[b]{2}{*}{ Sig. } \\
\hline & & B & Std. Error & & & \\
\hline 1 & (Constant) & 15.731 & 2.032 & & 7.741 & .000 \\
\hline & $\begin{array}{l}\mathrm{x} 1=\text { ketidakpuasan } \\
\text { konsumen }\end{array}$ & .256 & .231 & .159 & 1.112 & .269 \\
\hline & interaksi $x 1^{*} z$ & .019 & .003 & .783 & 5.489 & .000 \\
\hline
\end{tabular}

Sumber: Data Primer diolah dengan SPSS Th.2018

Berdasarkan hasil analisis regresi linear bertingkat diperoleh persamaan sebagai berikut:

$$
\begin{aligned}
& Y=\alpha+\beta_{1} X_{1} * Z \\
& Y=15.731+0,019 X_{1} * Z
\end{aligned}
$$

Dari persamaan variabel moderasi diketahui nilai $\mathrm{t}$ hitung interaksi ketidakpuasan konsumen dengan kebutuhan mencari variasi sebesar 5,489 dengan nilai signifikan yaitu 0,000. Dapat disimpulkan bahwa variabel kebutuhan mencari variasi memperkuat hubungan antara ketidakpuasan konsumen dengan keputusan perpindahan merek.

\section{Karakteristik Kategori Produk}

\begin{tabular}{|c|c|c|c|c|c|c|}
\hline \multirow{2}{*}{\multicolumn{2}{|c|}{ Model }} & \multicolumn{2}{|c|}{ Unstandardized Coefficients } & \multirow{2}{*}{$\begin{array}{c}\begin{array}{c}\text { Standardized } \\
\text { Coefficients }\end{array} \\
\text { Beta }\end{array}$} & \multirow[b]{2}{*}{$\mathrm{t}$} & \multirow[b]{2}{*}{ Sig. } \\
\hline & & B & Std. Error & & & \\
\hline \multirow[t]{3}{*}{1} & (Constant) & 21.674 & 2.048 & & 10.581 & .000 \\
\hline & $\begin{array}{l}\text { x2 = karakteristik kategori } \\
\text { produk }\end{array}$ & -.451 & .313 & -.241 & -1.443 & .152 \\
\hline & interaksi $\times 2^{*} z$ & .033 & .005 & 1.145 & 6.856 & .000 \\
\hline
\end{tabular}

Coefficients $^{\mathrm{a}}$

Sumber: Data Primer diolah dengan SPSS Th.2018

Berdasarkan hasil analisis regresi linear bertingkat diperoleh persamaan sebagai berikut:

$$
\begin{aligned}
& Y=\alpha+\beta_{2} X_{2} * Z \\
& Y=21,674-0,451 X_{2}+0,33 X_{2} * Z
\end{aligned}
$$

Dari persamaan variabel moderasi diketahui nilai $\mathrm{t}$ hitung interaksi karakteristik kategori produk dengan kebutuhan mencari variasi sebesar 6,856 dengan nilai signifikan yaitu 0,000. Dapat disimpulkan bahwa variabel kebutuhan mencari variasi memperkuat hubungan antara karakteristik kategori produk dengan keputusan perpindahan merek. 


\section{Uji Hipotesis}

\section{a. Uji F}

Tabel 20

Hasil Analisis Uji F

ANOVA $^{\text {b }}$

\begin{tabular}{|ll|r|r|r|r|r|}
\hline Model & & Sum of Squares & df & Mean Square & F & Sig. \\
\hline 1 & Regression & 1762.840 & 2 & 881.420 & 531.304 & $.000^{\mathrm{a}}$ \\
& Residual & 160.920 & 97 & 1.659 & & \\
Total & 1923.760 & 99 & & & \\
\hline
\end{tabular}

Sumber: Data Primer diolah dengan SPSS Th.2018

\section{b. Uji T}

Tabel 21

\section{Hasil Analisis Uji T}

Coefficients $^{\mathrm{a}}$

\begin{tabular}{|c|c|c|c|c|c|}
\hline \multirow[b]{2}{*}{ Model } & \multicolumn{2}{|c|}{$\begin{array}{l}\text { Unstandardized } \\
\text { Coefficients }\end{array}$} & \multirow{2}{*}{\begin{tabular}{|c|}
$\begin{array}{c}\text { Standardized } \\
\text { Coefficients }\end{array}$ \\
Beta \\
\end{tabular}} & \multirow[b]{2}{*}{$\mathrm{t}$} & \multirow[b]{2}{*}{ Sig. } \\
\hline & B & Std. Error & & & \\
\hline $1 \quad$ (Constant) & 4.520 & 1.076 & & 4.200 & .000 \\
\hline $\begin{array}{l}\mathrm{x} 1=\text { ketidakpuasan } \\
\text { konsumen }\end{array}$ & .980 & .072 & .607 & 13.608 & .000 \\
\hline $\begin{array}{l}\mathrm{x} 2=\text { Karakteristik } \\
\text { kategori produk }\end{array}$ & .773 & .083 & .413 & 9.268 & .000 \\
\hline
\end{tabular}

Sumber: Data Primer diolah dengan SPSS Th.2018

Berdasarkan hasil pengolahan data diatas pada tabel 21 hasil uji t parsial, maka dapat disimpulkan bahwa:

1. Dari tabel diatas terlihat bahwa ketidakpuasan konsumen memiliki nilai koefisien regresi positif dengan nilai t hitung sebesar 13,608 dengan nilai sig sebesar 0,000. Jika dibandingkan dengan ( $\mathrm{t}$ tabel, sig 0.05, df (100-4) $=$ 96). Maka dapat terlihat bahwa dengan nilai t hitung 13,608 > t tabel 1,660, dan nilai sig $0,000<0.05$, maka dapat disimpulkan bahwa Ha diterima dan Ho ditolak artinya bahwa ketidakpuasan konsumen berpengaruh dan signifikan terhadap keputusan perpindahan merek.

2. Dari tabel diatas terlihat bahwa karakteristik kategori produk memiliki nilai koefisien regresi positif dengan nilai t hitung sebesar 9,268 dengan nilai sig sebesar 0,000. Jika dibandingkan dengan ( t tabel, sig 0.05, df $(100-4)=96$ ). Maka dapat terlihat bahwa dengan nilai t hitung 9,268>t tabel 1,660, dan nilai sig $0,000<0.05$, maka dapat disimpulkan bahwa Ha diterima dan Ho ditolak artinya bahwa karakteristik kategori produk berpengaruh dan signifikan terhadap keputusan perpindahan merek. 


\section{c. Koefisien Determinasi $\mathbf{R}^{2}$}

Tabel 22

Hasil Analisis Koefisien Determinasi R2

Model Summary ${ }^{\mathrm{b}}$

\begin{tabular}{|l|r|r|r|r|}
\hline Model & R & R Square & Adjusted R Square & $\begin{array}{c}\text { Std. Error of the } \\
\text { Estimate }\end{array}$ \\
\hline 1 & $.957^{\mathrm{a}}$ & .916 & .915 & 1.28801 \\
\hline
\end{tabular}

Sumber: Data Primer diolah dengan SPSS Th.2018

\section{SIMPULAN}

Berdasarkan hasil pengujian dan pembahasan mengenai pengaruh ketidakpuasan konsumen karakteristik kategori produk terhadap keputusan perpindahan merek dengan kebutuhan mencari variasi sebagai variabel moderasi pada CV.MAX-INDO, maka dapat ditarik kesimpulan, antara lain:

1. Dari tabel diatas terlihat bahwa ketidakpuasan konsumen memiliki nilai koefisien regresi positif dengan nilai t hitung sebesar 13,608 dengan nilai sig sebesar 0,000. Jika dibandingkan dengan (t tabel, sig 0.05, df (100-4) = 96). Maka dapat terlihat bahwa dengan nilai $\mathrm{t}$ hitung 13,608 > t tabel 1,660, dan nilai sig $0,000<0.05$, maka dapat disimpulkan bahwa Ha diterima dan Ho ditolak artinya bahwa ketidakpuasan konsumen berpengaruh dan signifikan terhadap keputusan perpindahan merek.

2. Dari tabel diatas terlihat bahwa karakteristik kategori produk memiliki nilai koefisien regresi positif dengan nilai t hitung sebesar 9,268 dengan nilai sig sebesar 0,000. Jika dibandingkan dengan (t tabel, sig 0.05, df $(100-4)=96)$. Maka dapat terlihat bahwa dengan nilai $\mathrm{t}$ hitung 9,268 $>\mathrm{t}$ tabel 1,660, dan nilai sig $0,000<0.05$, maka dapat disimpulkan bahwa $\mathrm{Ha}$ diterima dan Ho ditolak artinya bahwa karakteristik kategori produk berpengaruh dan signifikan terhadap keputusan perpindahan merek.

3. Hasil uji regresi dengan menggunakan variabel moderasi diketahui bahwa variabel kebutuhan mencari variasi sebagai moderasi memperkuat hubungan antara ketidakpuasan konsumen dan karakteristik kategori produk terhadap keputusan perpindahan merek

4. Hasil estimasi dalam pengujian ini menjelaskan bahwa 91,5\% keputusan perpindahan merek dipengaruhi oleh ketidakpuasan konsumen dan karakteristik kategori produk. sedangkan sisanya 8,5\% disebabkan oleh hal-hal lain yang ada diluar penelitian seperti harga, kepercayaan, promosi, dan lain-lain.

\section{UCAPAN TERIMA KASIH}

Penulis mengucapakan terima kasih kepada:

Bapak Febryandhie Ananda, SE, M.Si selaku ketua STIE “KBP” Padang. Ibu Lidhya Marta, SE, MM selaku wakil ketua “STIE KBP” Padang.

Ibu Febsri Susanti, SEI, MM selaku ketua program studi manajemen dan dosen pembimbing skripsi yang sangat rendah hati dan membinbing kami dengan penuh kesabaran dari awal proposal penyelesaian skripsi. 
Ibu Maria Magdalena, SPd,M.M selaku dosen pembimbing akademik di STIE "KBP" Padang

Semua guru, dosen, dan staff yang telah berbagi ilmu dan waktunya sehingga membantu penulis menjadi orang yang memiliki ilmu dan dapat menyelesaikan tugas akhir ini.

Pimpinan CV.MAX-INDO Padang beserta karyawan yang telah memberi izin penulis untuk melakukan penelitian serta dalam memperoleh data.

\section{DAFTAR PUSTAKA}

Aaker, D. A. (1997). manajemen ekuitas merek, alih bahasa. Aris Ananda jakarta : mitra utama.

A Terence, S. (2003). periklanan promosi, aspek tambahan, komunikasi pemasaran terpadu. jakarta; erlangga.

Agustiono, Budi, S. (2006). No Title. Analisis Pengaruh Kualitas Pelayanan Jasa Terhadap Kepuasan Dan Loyalitas Pasien Rawat Inap Di Rumah Sakit St.Elisabeth Semarang, 1 No 1, 1-18.

Andika, A., \& Susanti, F. (2018). Pengaruh Marketing Mix Terhadap Keputusan Pembelian Parfum di Azzwars Parfum Lubeg Padang. https://doi.org/10.31227/osf.io/upgc3

Anggara, A., \& Mayliza, R. (2019). Pengaruh Ketidakpuasan Konsumen, Karakteristik Kategori Produk HP, Terhadap Keputusan Perpindahan Merek Pada Mahasiswa Regular Program Studi Manajemen Angkatan 2014-2015 STIE “KBP” Padang. https://doi.org/10.31219/osf.io/yfuzh

Arianto, A. B. (2013). jjPengaruh Atribut Produk, Harga, Kebutuhan Mencari Variasi dan Ketidakpuasan Konsumen terhadap Keputusan Perpindahan Merek dari Samsung Galaxy Series di Kota Malang. Anandhitya Bagus Arianto Nama Orang JURNAL APLIKASI MANAJEMEN, 11(2).

Arista, desi dan astuti, rahayu. sri. (2011). analisis pengaruh iklan, kepercayaan merek dan citra merek terhadap minat beli konsumen. Jurnal Aset, 13 nol(maret 2011), 37-45.

Aziz, N. (2019). Analisis Pengaruh Kualitas Produk, Harga, Promosi Terhadap Keputusan Pembelian Air Minum Dalam Kemasan (AMDK) Merek Aicos Produksi Pt. $\quad$ Bumi $\quad$ Sarimas https://doi.org/10.17605/OSF.IO/8XKYB

Budi Purbayu Santosa dan Ashari. (2005). Analisis Statistik dengan Microsoft Axcel \& SPSS. Yogyakarta, Andi Offset.

Caruana, A. (2002). service loyalty: the effects of service quality and the mediating role of customer satisfaction. European Journal of Marketing, 37 (7-8), 811-828. 
Dharmmesta, Bashu, S. (1999). loyalitas pelanggan. Jurnal Ekonomi Dan Bisnis Indonesia, 14 No 3.

Freddy Rangkuti. (2004). riset pemasaran. PT. Gramedia Pustaka Utama, Jakarta.

Junaidi, S. (2002). pengaruh ketidakpuasan konsumen karakteristik kategori produk dan kebutuhan mencari variasi terhadap keputusan perpindahan merek. Jurnal Ekonomi Dan Bisnis Indonesia.

Kotler, A. (2001). prinsip-prinsip pemasaran. jakarta ; erlangga.

Kotler, P. dan G. A. (1998). dasar-dasar pemasaran. Jakarta, PT. Prenhalindo.

Kotler, P. dan K. L. K. (2008). manajemen pemasaran, jilid I. Erlangga, Jakarta.

Marlius, D. (2017). Keputusan Pembelian Berdasarkan Faktor Psikologis Dan Bauran Pemasaran Pada PT. Intercom Mobilindo Padang. Jurnal Pundi. Volume 1. No. 1. Hal. 57-66. https://doi.org/10.31575/jp.v1i1.9

Marlius, D. (2016). Pengaruh Bauran Pemasaran Jasa Terhadap Minat Nasabah Dalam Menabung Pada Bank Nagari Cabang Muaralabuh. https://doi.org/10.31227/osf.io/vdqgx

Mayliza, R. (2019). Pengaruh Kesadaran Merek, Asosiasi Merek Dan Perception Of Quality Terhadap Keputusan Pembelian Hospital Bed Merek Paramout Di PT. Aga Medika Utama Padang (Studi Kasus Rumah Sakit Umum Kota Padang). https://doi.org/10.17605/OSF.IO/VYQ4E

Mayliza, R. (2019). Analisis Keputusan Pembelian Ulang Axis Ditinjau Dari Bauran Pemasaran Kasus Di Kota Padang. https://doi.org/10.31219/osf.io/e7xhy

Meidisa, C., \& Susanti, F. (2019). Pengaruh Preferensi Dan Pengetahuan Produk Terhadap Minat Menabung Masyarakat Pada Bank Nagari Unit Layanan Syariah Cabang Pasar Raya Padang. https://doi.org/10.31227/osf.io/bf7cr

Mudrajad Kuncoro. (2001). Metode Kuantitatif Teori Dan Aplikasi Untuk Bisnis Dan Ekonomi Edisi Pertama. Yogyakarta, UPP AMP YPKN.

Peter, J. P. dan J. C. O. (2002). consumer bahavior and marketing strategy sixth edition. MCGraw-Hill Irwin.

philip kotler. (2002). manajemen pemasaran, edisi millenium, jilid 2. PT.Prenhallindo, Jakarta.

Rosi, J., Farida, N., \& Budiatmo, A. (2012). Pengaruh, 1, 82-92.

setiadi, N. J. (2003). perilaku konsumen : konsep dan implikasi untuk strategi dan 
penelitian pemasaran. Jakarta : Kencana.

Sugiono, prof. D. (2000). stastistika untuk penelitian. bandung : alfabeta.

Sugiono, prof. D. (2006). Metode penelitian kuantitatif kualitatif dan R\&D. Bandung, Alfabeta.

Sugiono, prof. D. (2009). Metode penelitian bisnis (pendekatan kuantitatif, kualitatif, dan R\&D. Bandung, Alfabeta.

Sugiono, prof. D. (2012). memahami penelitian kualitatif. kota bandung, alfabeta.

Sugiono, prof. D. (2015). statistik non parametris untuk penelitian. kota bandung, penerbit alfabeta.

Suharseno, T., Hidayat, R., Ayu, D., \& Dewi, L. (2013). Kategori Produk Terhadap Keputusan Perpindahan Merek Dengan Kebutuhan Mencari Variasi Sebagai. Jurnal Bulletin Studi Ekonomi, 18(2), 176-182.

Supranoto, M. (2009). strategi menciptakan keunggulan bersaing produk melalui orientasi pasar, inovasi dan orientasi kewirausahaan dalam rangka meningkatkan kinerja pemasaran. Jurnal Sains Pemasaran Indonesia, vol 1.

Usman, H. (2003). Metodologi Penelitian Sosial. Jakarta, Bumi Aksara.

Waluyo, D. E. (2003). teori ekonomi makro. Malang: UMM.

Wibowo, S. F., Kurnaen, T., \& P, A. K. R. (2014). Pengaruh atribut produk dan variety seeking terhadap keputusan perpindahan merek handphone nokia ke smartphone samsung ( Survei pada outlet Okeshop ITC Roxy Mas , Jakarta Pusat ). Jurnal Riset Manajemen Sains Indonesia, 5(1), 21-41. 